\title{
Comparative Analysis of Agro-Morphological and Molecular Variations in Huskless Barley (Hordeum vulgare L.) under Central Agro-Climatic Zone of India
}

\author{
P. Banjarey ${ }^{1}$, P. Kumar ${ }^{1}$, S. Verma $^{2}$, A.N. Tikle ${ }^{1}$, R. Malik ${ }^{2}$, \\ A. Sarker ${ }^{3}$ and R.P.S. Verma ${ }^{3}$ \\ ${ }^{1}$ R.V.S.K.V.V. (Rajmata Vijayaraje Scindia Krishi Vishwa Vidyalaya) Gwalior-474002, India \\ ${ }^{2}$ ICAR-IIWBR, Karnal-132001, India \\ ${ }^{3}$ ICARDA-IRP (India Research Platform), Amlaha, India \\ *Corresponding author
}

\section{A B S T R A C T}

\begin{tabular}{l} 
K e y w o r d s \\
Huskless barley, \\
$\begin{array}{l}\text { SSR markers, } \\
\text { Heritability, Cluster } \\
\text { analysis. }\end{array}$ \\
Article Info \\
$\begin{array}{l}\text { Accepted: } \\
19 \text { October } 2017 \\
\text { Available Online: } \\
10 \text { December } 2017\end{array}$ \\
\hline
\end{tabular}

Keywords

Huskless barley,

SSR markers,

Heritability, Cluster analysis.

Article Info

Accepted:

Available Online

\section{Introduction}

Barley has been used for various purposes, such as animal feed, malting and brewing, while huskless barley has been used as human food. Barley is one of the cereals with the most diversified genetic basis (Baik and Ullrich, 2008). Based on this knowledge, quantitative and qualitative gains might be obtained in a more effective way during genotype selection and evaluation through appropriate traits, for use in future parent hybridization (Valls, 2007). Knowing the genetic diversity of barley germplasm is necessary for identifying diverse parental combinations and also creating segregating progeny with high genetic variability for selection. Morphological traits and molecular markers that reveal polymorphism at the DNA level have been shown as a very powerful tool for genotype characterization and estimation of genetic diversity (Salem et al., 2008). Therefore, in the present investigation, accessions of hull-less barley received from ICARDA, were evaluated for agro-morphological and genetic diversity present among them and to classify them in Indian conditions at ICARDA-India Research 
Platform (ICARDA-IRP), Amlaha (M.P.). The purpose of this study is to identify best performing accessions to improve production in barley growing areas of central India and for utilization in other breeding programmes for specific purposes. The present study was undertaken to determine the diversity for agro-morphological traits and estimate the genetic distance by molecular markers. This classification of the huskless genotypes will help identification of promising trait-specific genotypes for utilization by breeders in genetic enhancement research, at national and international level.

\section{Materials and Methods}

\section{Plant material}

The 24 barley accessions from ICARDA, Lebanon grown at experimental field of ICARDA- IRP (India Research Platform), Amlaha, $\left(27^{\circ} 12^{\prime} \mathrm{N}, 77^{\circ} 05^{\prime} \mathrm{E}\right)$ in RBD design with 2 replications in 6 row plots of $25 \mathrm{~cm}$ distance between rows. Sowing was done on Nov. 12, 2014 during the rabi (winter) season of $2014-15$. $50 \%$ of Nitrogen $(30 \mathrm{~kg}$ ), full dose of Phosphorus $(60 \mathrm{~kg})$ and Potassium (40kg) were applied at the sowing as basal dose. Top dressing of remaining Nitrogen was done after 30 days of sowing.

Crop was maintained under rainfed condition. First hand weeding was done with the appearance of thick flush of weeds. Second hand weeding was repeated after two weeks.

\section{Phenotypic screening}

Data was recorded for taking 10 randomly competitive plants from the middle row for each accession for nine agro-morphological traits viz. plant height, tillers per plant, days to heading, numbers of spikes per plant, spike length, spikelets per spike, grains per spike, 1000 grain weight and yield per plant.

\section{DNA isolation}

Equal number of fresh young leaves (two weeks old seedlings) of at least six from each genotype was bulked for DNA extraction. Total genomic DNA was isolated using the modified CTAB plants method (Saghai Maroof et al., 1984).

The DNA samples were analyzed both qualitatively and quantitatively using $0.8 \%$ agarose gel electrophoresis.

\section{Generation of SSR markers based molecular profiles}

Total 90 SSR markers from different locations of each linkage group of barley genome were selected out and 43 markers showed polymorphism (Table 2).

The necessary details of these primer pairs were obtained from website (www.wheat. pw.usda.gov/cgi-bin/graingenes.com). The PCR reaction was conducted in a reaction volume of $10 \mu \mathrm{l}$ containing $1 \mathrm{X}$ PCR buffer, $200 \mathrm{~m}$ MdNTPs, $0.25 \mu \mathrm{M}$ of primer, $2 \mathrm{Mm}$ $\mathrm{MgCl} 2$, 1u Taq polymerase and $50 \mathrm{ng}$ template DNA. PCR amplification was performed using BIORAD S 1000 thermocycler.

PCR products were resolved by electrophoresis on $2.5 \%$ agarose gels (HiMedia) at $4 \mathrm{v} / \mathrm{cm}$ in $0.5 \mathrm{X}$ TBE buffer. Fragment sizes were approximately calculated by interpolation from the migration distance of marker fragments of 100- bpDNA ladder (NEB, UK) and corroborated with the reported amplified fragment size of respective molecular marker. The occurrence of 'null' alleles was verified by re-amplification under similar PCR conditions. Gels were stained with ethidium bromide $(0.5 \mathrm{ug} / \mathrm{ml})$ and DNA banding patterns were visualized under UV light (Syngene Synoptics Ltd. USA). 


\section{Data analysis}

Cluster analysis was also done through multivariate analysis under the software SPSS (v23). Genetic divergence among the genotypes was assessed by using Euclidean $\mathrm{D}^{2}$ technique. Molecular weights for microsatellite products, in base pairs, were estimated and the summary statistics including the number of alleles per locus, and frequency of major alleles were determined. Polymorphic information content (PIC) was calculated for each SSR marker wise estimates of the discriminatory power of locus by taking into account the numbers of alleles that are expressed (Anderson et al., 1993). PIC value were calculated as

$\mathrm{PIC}=1-\sum P_{i j}^{2}$

Where, ${ }^{P_{i j}^{2}}$ is the frequency of the ${ }^{i^{t h}}$ allele.

Allele molecular weight data were also used to export the data in binary format (allele presence $=$ " $1 "$ and allele absence $=$ " $0 ")$ and entered into a matrix. Based on the matrix of (GD) values, SPSS software (v23) was used to obtain the dendrograms, Hierarchical Clustering, depicting Genetic relatedness of the accessions.

\section{Results and Discussion}

Evaluation of the amount of genetic variation in huskless barley germplasm is the essential study for barley breeding. Outcomes of the assessments provide a general guide for choosing parental lines to make suitable cross combinations for particular breeding purposes. In present investigation, 24 genotypes from ICARDA, Lebanon were grown at ICARDA-IRP (IRP), Amlaha (M.P.) to check their morphological diversity in Indian agro-climatic conditions and further evaluate them at molecular level for genetic variation.

\section{Genetic variability at agro-morphological level}

A total of nine agro- morphological characters i.e. plant height, tillers per plant, days to heading, numbers of spikes per plant, spike length, spilkelets per spike, grains per spike, 1000grain weight and yield per plant were recorded for analyses. As summarized in table 1 , spikelets per spike (75.40), spike length (74.55) and grains per spike (62.20) had shown highest heritability, moderate heritability was observed for tillers per plant (41.20), days to heading (41.12), 1000 grain weight (24.33) and yield per plant (24.33)while, plant height (9.45) and spikes per plant (7.55) had least heritability. For contributing toward divergence, 1000 grain weight (TGW) and yield per plant (Y/P) contributed maximum to divergence with phenotypic coefficient of variance (PCV)40.107 followed by spikelet per spike (S/E) with PCV 36.562. However trait like spike length (EL) and plant height (PH)had contributed least toward divergence with PCV 12.841 and 14.608, respectively. Abebe et al., (2010); Ibrahim et al., (2011); Yadav et al., (2015); have also recorded similar results for these characters for diversity assessment of barley in their studies.

\section{Clustering based on phenotypic variations}

The average of two replications of all the studied characters of the accessions was used to construct a similarity matrix using the SPSS (v23) software package. Though all the accessions developed had same centre of origin, still significant diversity was observed and grouped these genotypes in two major groups for phenotypic traits studied. The dendrogram clustered 18 accessions and 6 accessions into group 2 at G.S. $=0.01$ (Fig. 1). The Major group (1) is further divided into two sub groups, $\mathrm{A}$ and $\mathrm{B}$, containing 13 and 5 accessions respectively. Present grouping 
showed that the accessions having various or distant parents but in same environment didn't show any significant difference in their phenotypic performance. While accessions with either of the same or closely related parent have been clustered in different groups. Ibrahim et al., (2011) also observed grouping of ICARDA genotypes developed from diverse ancestors in same cluster on basis of their morphological traits in given climate.

\section{Molecular markers based genetic variability}

Several studies were conducted in world to evaluate the genetic relationships among different barley genotypes using molecular markers (Hou et al., 2005; Ferreira et al., 2016). Pejic et al., (1998) reported that the information of polymorphism would be sufficient if more than 70 alleles were detected. In our study, 43 polymorphic SSR markers randomly distributed across seven chromosomes of barley genome were screened with selected set of genotypes. These markers amplified 119 bands with an average of 2.76 bands per locus (Table 2).

In previous reports, Yadav et al., (2015) and Verma et al., (2015) also reported similar number of alleles in Indian barley during genetic variability studies. Whereas, Ivandic et al., (2002) and Maniruzzaman et al., (2014) reported 5.5 and 7.8 alleles per locus, respectively. Accessions screened in this study are from same centre and their pedigree gene pool is also narrow as there were bred for high yield, therefore, chances of getting fewer alleles per locus are expected and despite this they are robust enough to distinguish different accessions. In our study, chromosome 2 (2H) was found most polymorphic at molecular level across the linkage groups of barley. Previously Yadav et al., (2015) and Verma et al., (2015) also reported similar observations for Indian barley. Spanic et al., (2012) reported that greater than 0.50 PIC values indicate that SSR markers enable a high level of polymorphism. The PIC values in this study ranged from 0.153 to 0.81 with an average of 0.5 thus indicating sufficient variability in ICARDA accessions at molecular level (Fig. 2). MWG684 marker gave maximum polymorphism with PIC value 0.810 and 5 different allele sizes followed by marker HVM36 and HVM40with PIC value 0.722, 0.593 respectively and 5 different allele sizes. These results were comparable with results reported by Hua W. et al., (2015), Verma et al., (2015) and Yadav et al., (2015). Yadav et al., (2015) reported PIC range of 0.28 to 0.80 in Indian barley.

\section{Clustering based on molecular screening}

Using binary data of alleles, Sm matrix was generated to develop cluster of accessions based in molecular screening by SPSS software (v23). It revealed that INBYT-HI 14 and INBYT-HI 1 are most similar accessions with highest value of similarity matrix, 0.9075, further accessions INBYT-HI 14 and INBYT-HI 15 with similarity matrix value 0.899 observed to be very closely related. However, maximum distantly related genotypes are INBYT-HI 1 and INBYT-HI 17 with similarity matrix value 0.378 followed by INBYT-HI 1 and INBYT-HI 16 with similarity matrix value 0.386 . Genotypes with higher value of similarity matrix had one or another ancestor same in their pedigree. On basis of genetic variability all accessions were clustered into two major groups with 20 accessions in group 1 and only four accessions in smaller group 2. Group1 was further divided into subgroups i.e. subgroup A with 14 accessions and subgroup B with 6 accessions. Similar results of clustering of genotypes of common ancestor in single group were observed by Wang et al., (2010). Zakova et al., (2006) got similar results for spring barley accessions. 
Fig.1 Clustering of ICARDA accessions on the basis of nine agro-morphological data using SPSS v23 software program

\section{Dendrogram using Average Linkage (Between Groups)}

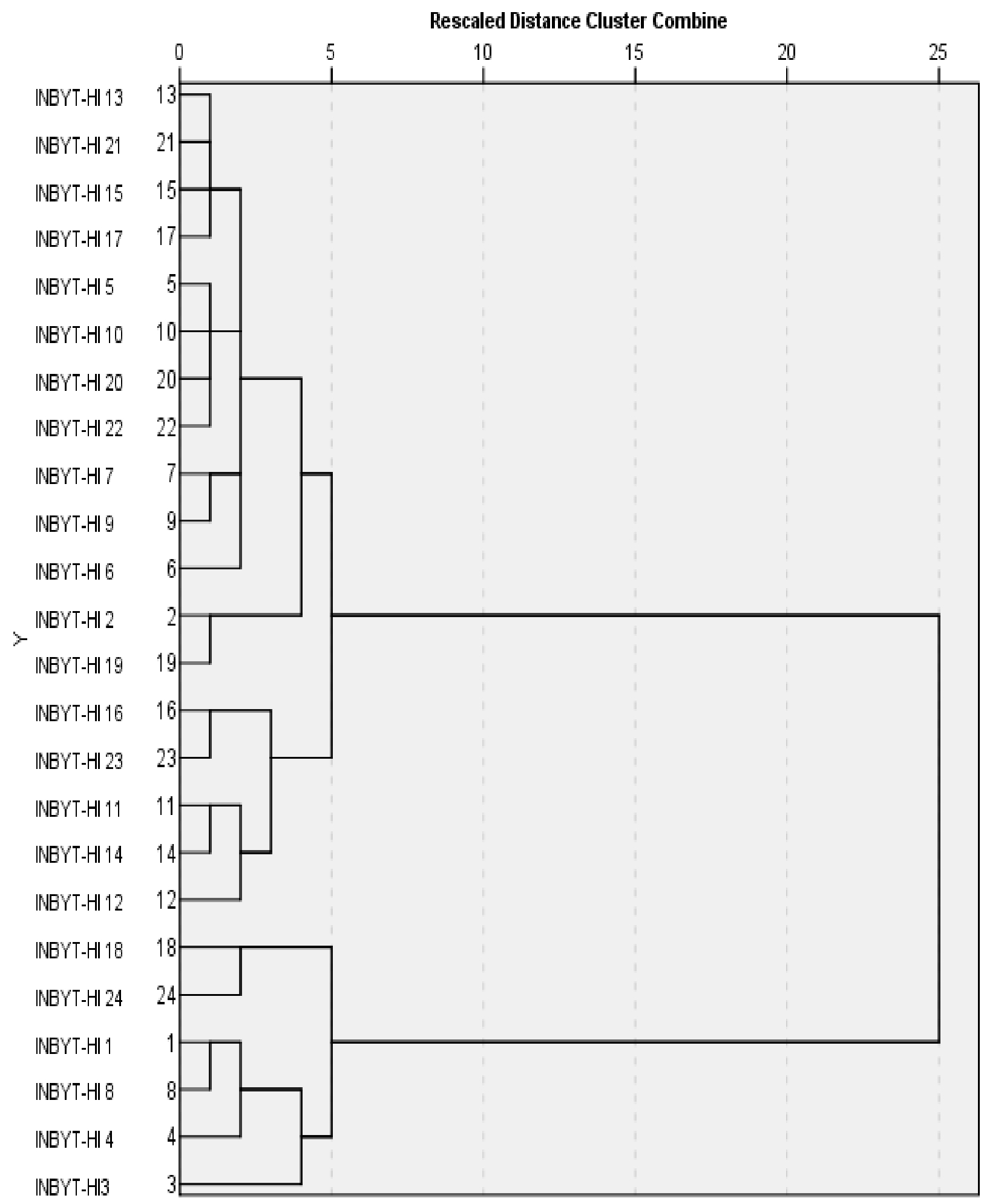


Fig.2 Clustering of ICARDA accessions on the basis of microsatellite markers using SPSS v23 software program

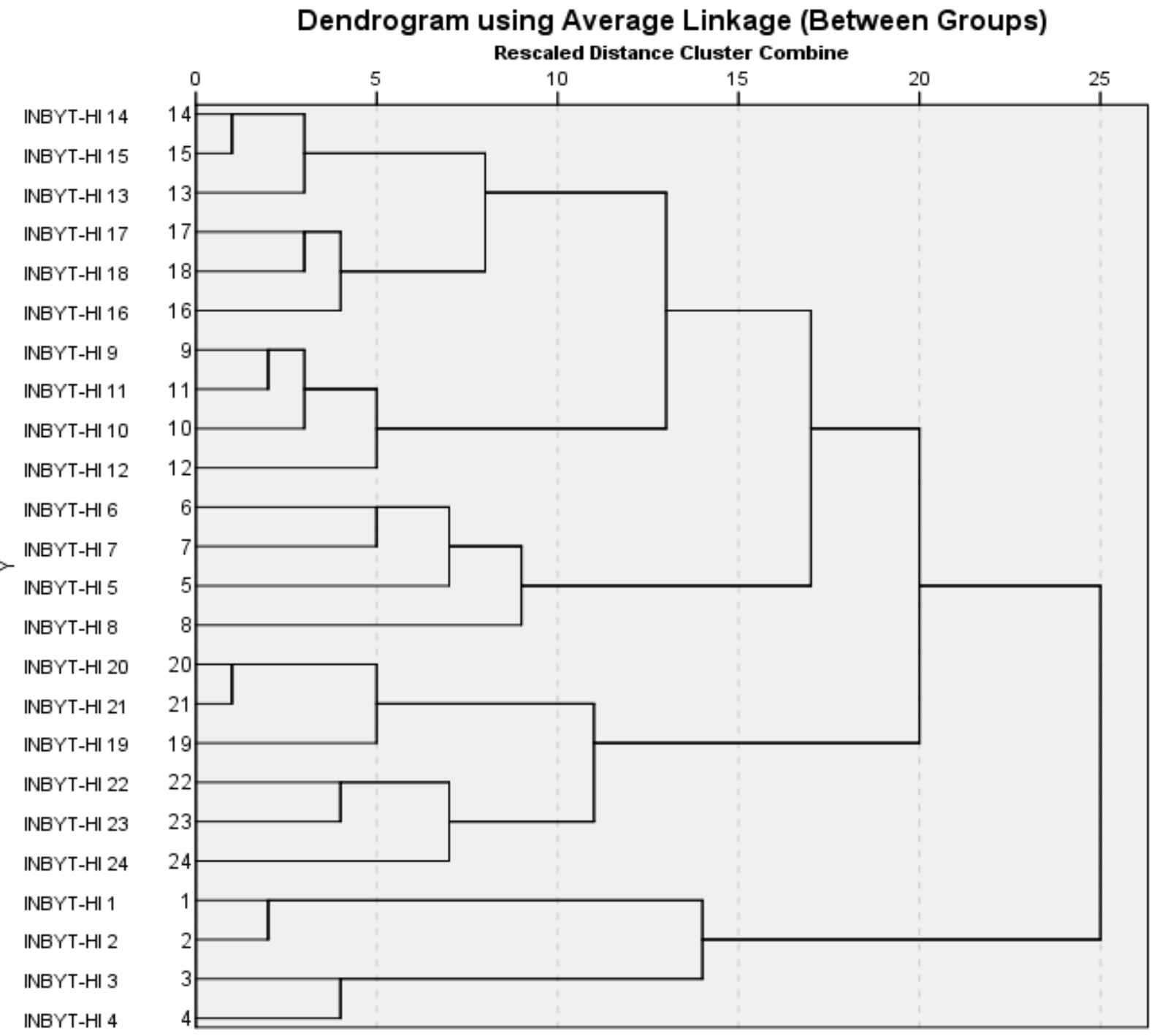

Table.1 Estimates of genetic parameters for different quantitative and qualitative characters of barley at ICARDA- IRP, Amlaha, Madhya Pradesh, India

\begin{tabular}{|c|c|c|c|c|c|c|c|c|c|}
\hline Parameter & PH & T/P & DH & S/P & SL & Sp/S & GN & TGW & Y/P \\
\hline Heritability & 9.454 & 41.203 & 41.122 & 7.556 & 74.135 & 75.405 & 62.204 & 24.331 & 24.331 \\
\hline GCV & 4.492 & 20.213 & 20.08 & 3.53 & 31.111 & 31.749 & 18.6 & 19.784 & 19.784 \\
\hline PCV & 14.608 & 31.489 & 31.314 & 12.841 & 36.132 & 36.562 & 23.584 & 40.107 & 40.107 \\
\hline Genetic Advance & 2.157 & 3.253 & 3.221 & 0.156 & 30.667 & 30.936 & 15.147 & 2.07 & 10.349 \\
\hline $\begin{array}{c}\text { Genetic Advance } \\
\text { value \% means }\end{array}$ & 2.845 & 26.727 & 26.526 & 1.999 & 55.181 & 56.794 & 30.22 & 20.103 & 20.103 \\
\hline
\end{tabular}

$P H=$ Plant height,$T / P=$ Tillers $/$ plant,$D H=$ Days to heading, $S / P=$ Spikes per plant,$S L=$ Spike Length, Sp/S = Spikelet per spike, $G N=$ Grains per spike, $T S W=1000$ grains weight, $Y / P=$ Yield $/$ Plant, GCV $=$ Genotypic Coefficient of Variance, PCV=Phenotypic Coefficient of Variance 
Table.2 Allelic variation of the polymorphic SSR loci in barley genotypes on the basis of allele richness and PIC

\begin{tabular}{|c|c|c|c|c|c|c|c|}
\hline $\begin{array}{l}\text { Primer's } \\
\text { name }\end{array}$ & Chr & $\operatorname{Tm}(\mathrm{c})$ & $\begin{array}{l}\text { No.of } \\
\text { Alleles }\end{array}$ & $\begin{array}{l}\text { Allels size } \\
\text { range }(b p)\end{array}$ & $\begin{array}{c}\text { High } \\
\text { frequency } \\
\text { allele }\end{array}$ & $\begin{array}{l}\% \text { of high } \\
\text { frequency } \\
\text { allele }\end{array}$ & PIC \\
\hline Bmag211 & $1 \mathrm{H}$ & 58 & 4 & $156-176$ & 166 & 37.50 & 0.52 \\
\hline ABG500a & $1 \mathrm{H}$ & 55 & 3 & $170-189$ & 155 & 30.00 & 0.59 \\
\hline Bmag105 & $1 \mathrm{H}$ & 60 & 2 & $100-108$ & 100 & 37.50 & 0.47 \\
\hline Bmag213 & $1 \mathrm{H}$ & 55 & 2 & $150-180$ & $150-180$ & 30.00 & 0.50 \\
\hline Scssr10477 & $1 \mathrm{H}$ & 55 & 2 & $110-130$ & 130 & 32.50 & 0.50 \\
\hline Bmag829 & $2 \mathrm{H}$ & 55 & 3 & $170-189$ & 180 & 32.50 & 0.59 \\
\hline HVM54 & $2 \mathrm{H}$ & 55 & 3 & $110-159$ & 130 & 30.00 & 0.59 \\
\hline Bmag749 & $2 \mathrm{H}$ & 55 & 3 & $120-166$ & 110 & 47.50 & 0.34 \\
\hline Bmac576 & $2 \mathrm{H}$ & 53 & 3 & $100-160$ & 149 & 27.50 & 0.64 \\
\hline EBmac640 & $2 \mathrm{H}$ & 58 & 3 & $110-176$ & 176 & 32.50 & 0.60 \\
\hline Bmac129 & $2 \mathrm{H}$ & 58 & 4 & $100-150$ & 145 & 27.50 & 0.68 \\
\hline $\mathrm{ABC} 252$ & $2 \mathrm{H}$ & 58 & 3 & $200-250$ & 250 & 45.00 & 0.47 \\
\hline ABG058 & $2 \mathrm{H}$ & 60 & 3 & $280-330$ & 330 & 30.00 & 0.62 \\
\hline HVM36 & $2 \mathrm{H}$ & 55 & 5 & $100-150$ & 120 & 27.50 & 0.72 \\
\hline Bmag877 & $3 \mathrm{H}$ & 55 & 3 & $120-153$ & $140-153$ & 22.50 & 0.68 \\
\hline Bmag225 & $3 \mathrm{H}$ & 58 & 4 & $110-162$ & 140 & 37.50 & 0.50 \\
\hline EBmac705 & $3 \mathrm{H}$ & 55 & 2 & $140-150$ & $140-150$ & 30.00 & 0.50 \\
\hline ABG471 & $3 \mathrm{H}$ & 58 & 3 & $940-1000$ & 980 & 45.00 & 0.27 \\
\hline ABG70 & $3 \mathrm{H}$ & 58 & 3 & $400-490$ & 490 & 35.00 & 0.55 \\
\hline Bmag0013 & $3 \mathrm{H}$ & 58 & 2 & $140-155$ & 140 & 35.00 & 0.49 \\
\hline HVM14 & $4 \mathrm{H}$ & 55 & 2 & $120-158$ & 158 & 45.00 & 0.38 \\
\hline ABG500b & $4 \mathrm{H}$ & 58 & 2 & $180-189$ & $180-189$ & 30.00 & 0.50 \\
\hline MWG634 & $4 \mathrm{H}$ & 58 & 2 & $880-900$ & 900 & 50.00 & 0.28 \\
\hline Bmac175 & $4 \mathrm{H}$ & 58 & 2 & $145-155$ & 155 & 35.00 & 0.49 \\
\hline HVM40 & $4 \mathrm{H}$ & 55 & 5 & $130-170$ & 140 & 17.50 & 0.59 \\
\hline $\mathrm{ABC} 483$ & $5 \mathrm{H}$ & 58 & 2 & $500-510$ & 510 & 37.50 & 0.47 \\
\hline Bmag812 & $5 \mathrm{H}$ & 55 & 2 & $120-157$ & 157 & 50.00 & 0.28 \\
\hline Bmag222 & $5 \mathrm{H}$ & 58 & 3 & $140-179$ & 160 & 27.50 & 0.64 \\
\hline $\mathrm{ABC} 302$ & $5 \mathrm{H}$ & 58 & 3 & $980-1100$ & 1100 & 45.00 & 0.41 \\
\hline GMS61 & $5 \mathrm{H}$ & 60 & 2 & $300-310$ & 310 & 45.00 & 0.38 \\
\hline Bmag387 & $5 \mathrm{H}$ & 58 & 2 & $110-150$ & 150 & 42.50 & 0.41 \\
\hline Bmag163 & $5 \mathrm{H}$ & 55 & 3 & $110-150$ & 150 & 27.50 & 0.62 \\
\hline Bmag760 & $5 \mathrm{H}$ & 55 & 3 & $110-130$ & 160 & 27.50 & 0.68 \\
\hline MWG684 & $6 \mathrm{H}$ & 58 & 5 & $150-210$ & 210 & 15.00 & 0.81 \\
\hline HVM67 & $6 \mathrm{H}$ & 55 & 2 & $110-120$ & 110 & 40.00 & 0.44 \\
\hline MWG798 & $6 \mathrm{H}$ & 58 & 2 & $350-370$ & 350 & 40.00 & 0.44 \\
\hline Bmac0040 & $6 \mathrm{H}$ & 58 & 3 & $200-236$ & 236 & 30.00 & 0.59 \\
\hline Bmac64 & $7 \mathrm{H}$ & 58 & 2 & $130-155$ & 155 & 47.50 & 0.35 \\
\hline Bmag273 & $7 \mathrm{H}$ & 55 & 2 & $120-186$ & 186 & 55.00 & 0.15 \\
\hline Bmag341 & $7 \mathrm{H}$ & 55 & 3 & $140-200$ & 158 & 37.50 & 0.54 \\
\hline Bmac162 & $7 \mathrm{H}$ & 58 & 3 & $160-187$ & 170 & 30.00 & 0.61 \\
\hline bmag 110 & $7 \mathrm{H}$ & 58 & 2 & $130-145$ & 145 & 37.50 & 0.47 \\
\hline Bmac224 & $7 \mathrm{H}$ & 55 & 2 & $166-176$ & 176 & 45.00 & 0.38 \\
\hline
\end{tabular}

Tm = Annealing Temperature, PIC = Polymorphism Information content. 
Similar level of genetic similarity values were reported for Indian barley during UPGMA based clustering (Verma et al., 2015 and Yadav et al., 2015)

\section{Phenotypic and molecular comparitive analyses}

The mantel correspondance test (Mantel, 1967) was used to compare the molecular and morphological similarity matrics. Correlation between the distance coefficient was observed low $(\mathrm{r}=0.01204, \mathrm{p}=0.5798)$. Both morphological and molecular dendrograms clustered the accessions into two major clusters and 1-2 minor groups.

Molecular dendrogram cluster the different accessions into same groups which are not in the same group while clustering have been done for agro-morphological variations Correlation between the distance coefficient was low ( $\mathrm{r}=$ $0.01204, \mathrm{p}=0.5798)$ during mantel correspondance test for molecular and morphological similarity matrics. Although dendrograms clustered the accessions into major and minor groups.

As reported earlier, there is no need to be a necessarily positive correlation between morphological and molecular markers specialy SSRs because of their genetic nature, as there are studies (Zhang et al., 2010) revealing no or low correlation in this regard. Nevertheless, the genetic relationship observed using molecular markers may provide information on the history and biology of accessions or genotypes, but does not necessarily reflect what may be observed with respect to agro-morphological traits (Metais et al., 2000). The present study's results were in agreement with finding of several authors in different crops like in wheat (Salem et al., 2008); faba bean (Ammer et al., 2015), maize (Beyene et al., 2005) and barley (Amabile et al., 2013 and Singh et al., 2014). The knowledge about the genetic relationships of genotypes provides useful information to address breeding program and germplasm resource management. In present study, accessions performance evaluated in Indian condition can be further used for introduction or hybridization in any breeding program for any specific purpose enriching gene pool of barley in Indian. Markers information used in conjunction with morphological data, classified genotypes better than classifications based on individual data set i.e. morphological or molecular data. Genotypes selected through selection index can be evaluated in other agroclimatic zones of India for further utilization.

\section{References}

Abebe T.D., Bauer A.M. and Leon J. (2010).Morphological diversity of Ethiopian barley (Hordeum vulgare L.) in relation to geographic regions and altitudes. Hereditas, 147(4): 154-64.

Amabile R. F., Faleiro F. G., Vieira E. A., Peixoto J. R., Capettini F. and Júnior W. Q. R. (2013) Genetic diversity of irrigated barley based on molecular and quantitative data and on malting quality. Pesquisa Agropecuária Brasileira, 48(7): 748-756.

Ammer M. H., Alghamdi S. S., Migdadi H. M., Khan M. A., El- Harty E. H. and Al-Faifi, S. A. (2015). Assessment of genetic diversity among faba bean genotypes using agro-morphological and molecular markers.Saudi J. Biological Sciences,22; 340-50.

Anderson J.A., Churchill G.A., Autrique J.E., Tanksley S.D. and Sorrells M.E.(1993). Optimizing parental selection for genetic linkage maps, Genome, 36; 181-186.

Baik, B.K. and Ullrich, S.E. (2008). Barley for food: characteristics, improvement, and renewed interest. J. Cereal Science, 48(2): 233-242.

Beyene Y, Botha Anna-M and Myburg A A. (2005).A comparative study of molecular and morphological methods of describing genetic relationships in traditional Ethiopian highland maize. African Journal Biotechnology, 4(7): 586-95.

Ferreira, J. R., Pereira, J. F., Turchetto, C., Minella, E., Consoli, L., and Delatorre, C. A. (2016). Assessment of genetic diversity in Brazilian barley using SSR markers. 
Genetics and Molecular Biology, 39(1): 86-96.

Hou Y.C., Yan Z.H., Lan X.J., Wei Y.M., Zheng Y.L. (2005). Genetic diversity among barley germplasm with known origin based on the RAMP and ISSR markers. Scientia Agricultura Sinica, 38(12): 2555-2565.

Ibrahim O.M., Mohamed M.H., Tawfik M.M. and Badr E. A. (2011). Genetic Diversity Assessment of Barley (Hordeum vulgare L.) genotypes using Cluster Analysis. International J. Academic Research. 3(2): 81-85.

Ivandic V., Hackett C.A., Nevo E., Keith R., Thomas W.T.B., Forster B.P. (2002). Analysis of simple sequence repeats (SSRs) in wild barley from the Fertile Crecent: Associations with ecology, geography and flowering time. Plant Molecular Biology, 48(5-6): 511-527.

Maniruzzaman, Talukder Z., A., Rohman S., Begum F. and Amiruzzaman $M$. (2014).Polymorphism study in barley (Hordeum vulgare) genotypes using microsatellite (SSR) markers. Bangladesh J. Agriculture Research, 39(1): 33-45.

Mantel N (1967). The detection of disease clustering and a generalized regression approach. Cancer Research, 27: 209-220.

Saghai-Maroof M.A., Soliman K.M., Jorgensen R.A. and Allard R.W. (1984). Ribosomal DNA sepacer-length polymorphism in barley: mendelian inheritance, chromosomal location and population dynamics. Proceeding of National Academy Science, 81: 8014-8019.

Salem K. F. M., El-Zanaty A.M. and Esmail R.M. (2008). Assessing wheat (Triticum aestivum L.) genetic diversity using morphological characters and microsatellite markers. World J. Agriculture Science, 4(5): 538544.

Singh P, Singh A K, Sharma M and Salgotra S K.
(2014).Genetic divergence study in improved bread wheat varieties (Triticum aestivum). African $J$. Agricultural Research 9(4): 507- 12.

Spanic, V., Buerstmayr, H. and Drezner G. (2012). Assessment of genetic diversity of wheat genotypes using microsatellite markers. Periodicum Biologorum. 114(1): 37-42.

Valls, J.F.M. (2007). Plant genetic resources. Brasília: Embrapa Genetic Resources and Biotechnology, Pp. 281305.

Verma S., Goyal V., Verma A., Kumar D., Singh J., Khippal A., Selvakumar R., Katare S., Kharub A.S., Verma RPS, Sharma I. and Malik R. (2015). Evaluating genetic variation in barley varieties at molecular level. International J. Tropical Agriculture, 33(3): 2217-21.

Wang J.M., Yang J.M., Zhu J.H., Jia Q.J., Tao Y.Z., (2010). Assessment of genetic diversity by simple sequence repeats markers among forty elite varieties in the germplasm for malting barley breeding. $J$. Zhejiang University Science B, 11(10): 792800.

Yadav S. K., Singh A. K. and Malik R. (2015).Genetic diversity analysis based on morphological traits and microsatellite markers in barley (Hordeum vulgar). Indian J. Agricultural Sciences, 85(10): 37-44.

Zakova, M. and Benkova, M. (2006). Characterization of spring barley accessions based on multivariate analysis. Communications in Biometry and Crop Science, 1(2): 124-134.

Zhang X, Zhang Y, Yan R, Han G, Hong F, Wang J, Cao K (2010). Genetic variation of white clover (Trifolium repens L.) collections from China detected by morphological traits, RAPD and SSR. African $J$. Biotechnology, 9(21): 3032-3041.

\section{How to cite this article:}

Banjarey, P., P. Kumar, S. Verma, A.N. Tikle, R. Malik, A. Sarker and Verma, R.P.S. 2017. Comparative Analysis of Agro-Morphological and Molecular Variations in Huskless Barley (Hordeum vulgare L.) under Central Agro-Climatic Zone of India. Int.J.Curr.Microbiol.App.Sci. 6(12): 2821-2829. doi: https://doi.org/10.20546/ijcmas.2017.612.328 